\title{
Critical Care Use during the Course of Serious IIIness
}

\author{
Theodore J. Iwashyna \\ Department of Medicine, Hospital of the University of Pennsylvania, Philadelphia, Pennsylvania
}

\begin{abstract}
Despite its expense and importance, it is unknown how common critical care use is. We describe longitudinal patterns of critical care use among a nationally representative cohort of elderly patients monitored from the onset of common serious illnesses. A retrospective population-based cohort study of elderly patients in fee-forservice Medicare is used, with 1,108,060 Medicare beneficiaries at least 68 years of age and newly diagnosed with serious illnesses: 1 of 9 malignancies, stroke, congestive heart failure, hip fracture, or myocardial infarction. Medicare inpatient hospital claims from diagnosis until death $(65.1 \%)$ or fixed-right censoring (more than 4 years) were reviewed. Distinct hospitalizations involving critical care use (intensive care unit or critical care unit) were counted and associated reimbursements were assessed; repeated use was defined as five or more such hospitalizations. Of the cohort, $54.9 \%$ used critical care at some time after diagnosis. Older patients were much less likely to ever use critical care (odds ratio, 0.31 ; comparing patients more than 90 years old with those 68-70 years old), even after adjustment. A total of 31,348 patients $(2.8 \%)$ were repeated users of critical care; they accounted for $\$ 3.6$ billion in hospital charges and $\$ 1.4$ billion in Medicare reimbursement. We conclude that critical care use is common in serious chronic illness and is not associated solely with preterminal hospitalizations. Use is uneven, and a minority of patients who repeatedly use critical care account for disproportionate costs.
\end{abstract}

Keywords: elderly; end-of-life care; intensive care use; health services research; Medicare claims

Critical care units represent the apex of technically intensive (and expensive) American medicine. By some estimates, perhaps $20 \%$ of inpatient dollars - and perhaps $1 \%$ of the gross domestic product-are spent in critical care units $(1,2)$. Such units integrate many specialties and diverse technologies, offering the possibility of survival to some patients who would otherwise die. However, intensive care also raises the specter of treatment for treatment's sake (1) and fears of a life prolonged needlessly by machines.

Most current approaches to studying this critical part of the health care system treat an intensive care unit stay as a distinct, self-contained event, somehow disconnected from the rest of the patient's experience. Exceptions include a few prominent studies that have looked at the intensive care unit as a preterminal event (3) and a handful that have looked at so-called bounceback rates (readmissions within a few days) (4-8). Yet critical care units are but one part of the medical armamentarium, and they can also be studied in the context of the overall course of

(Received in original form March 1, 2004; accepted in final form July 19, 2004) Supported by a grant from the National Institute on Aging (R-01 AG15326-01) to Nicholas Christakis.

Correspondence and requests for reprints should be addressed to Theodore J. Iwashyna, M.D., Ph.D., c/o Nicholas Christakis, Department of Medicine, 100 Centrex, 3400 Spruce Street, Philadelphia, PA 19103. E-mail: iwashyna@alumni. Princeton.edu

This article has an online supplement, which is accessible from this issue's table of contents online at www.atsjournals.org

Am J Respir Crit Care Med Vol 170. pp 981-986, 2004 Originally Published in Press as DOI: 10.1164/rccm.200403-2600C on July 21, 2004 Internet address: www.atsjournals.org a patient's disease. Thus, for different individuals or populations, critical care could be used never or repeatedly over several years.

Studying critical care from this longitudinal perspective offers complementary advantages relative to other approaches. Episodefocused analyses naturally draw attention to those few patients with unusually long or expensive stays, but they obscure the likelihood that there also exist patients with repeated visits. More generally, episode-focused approaches are disconnected from a population at risk for critical care and so cannot provide information about the population-based chances of critical care use (i.e., they are numerator-based rather than denominator-based studies). For example, they encourage a focus on short-term outcomes that has only recently been overcome. Episode-focused analyses prompt the oft-quoted statistic that $10-15 \%$ of all hospitalizations result in critical care use $(1,9,10)$. Studying critical care as a preterminal event similarly provides a narrow time horizon and prompts limited interest in the timing and frequency of critical care use in the overall arc of disease. Such a focus can also contribute to a misrepresentation of the nature of intensive care use: for example, $46 \%$ of deaths in the Study to Understand Prognoses and Preferences for Outcomes and Risks of Treatments (SUPPORT) among gravely ill patients, including two enrollment diagnoses requiring intensive care unit (ICU) admission, occurred within 3 days of receiving mechanical ventilation, and this can be (but should not be) misconstrued to mean that nearly half of mechanical ventilation use eventuates in death (3).

In the present article, we seek to extend prior work in important ways. Here we consider critical care as an approach to organizing the care of seriously ill elderly patients (1) and we examine the following general hypotheses:

1. Among elderly patients with serious disease, critical care use will be common; some patients will repeatedly use critical care.

2. There will be significant demographic variation in the use of critical care.

We address these questions from the perspective of an elderly patient newly diagnosed with a serious - but not necessarily terminal-illness, using a large, national cohort of patients.

Some parts of this work were previously presented in abstract form at the 2004 American Thoracic Society International Meeting in Orlando, Florida (11).

\section{METHODS}

\section{Patient Population}

To address these hypotheses, data are needed with the following properties: (1) the data should be based on an inception cohort of patients monitored from the onset of their disease until death years later; (2) the data should include heterogeneous types of disease to help distinguish the needs engendered by particular pathophysiologies from choices about care; and (3) the data should be broad in geographic scope to monitor patients across distinct sites of care. Given the foregoing parameters, we analyzed the Care after the Onset of Serious Illness (COSI) data set, a data set built on the basis of Medicare claims. Medicare data capture $96 \%$ of the American population older than 65 years (12). COSI is a population-based cohort of 1,164,790 elderly patients identified at the time of initial diagnosis with a serious illness in 1993: cancer of the lung, colon, pancreas, urinary tract, liver or biliary 
tract, head or neck, or central nervous system, as well as leukemia or lymphoma, stroke, congestive heart failure, hip fracture, or myocardial infarction. These diseases were chosen to represent diverse, common illnesses that account for the majority of deaths in the United States; we also required that these illnesses have an onset date that could be reliably determined from Medicare claims (13). For inclusion in the COSI sample patients had to be at least 68 years old to allow three prior years of claims to be examined so as to reliably exclude prevalent cases (14-18). Additional information on empanelment restrictions are available (see the online supplement).

Patients in COSI were monitored through the end of 1997, by which point nearly $65 \%$ had died. Patients were empaneled exclusively on the basis of their claims up to cohort inception, without reference to any future outcome or use of medical care.

\section{Definition of Critical Care Hospitalization}

Our outcome variable here is the use of critical care services during a hospitalization, as similarly implemented by others $(1,19,20)$. Medicare defines critical care services as those provided in separate units with round-the-clock nursing, equipment necessary to care for the critically ill, and a nurse-to-patient ratio of no more than 1 to 2 (21); critical care unit use is designated by hospitals, used for billing purposes, and therefore subject to audit, verification, and substantial penalties for fraud. This definition does not distinguish between coronary, surgical, medical, and mixed-use critical care $(1,20,22)$. By focusing on the use of critical care during a hospitalization, rather than the number of days it is used, we avoid the complications induced by interhospital variation in the availability of other monitored settings (e.g., telemetry) that might alter the timing of discharge from the unit, per se, without meaningfully altering the intensity of service provided. Of note, our study design allows us to track patients across multiple hospitals or states to assess their frequency of repeated use.

\section{Covariate Definitions}

All other diseases that patients may have had beyond their primary diagnosis (e.g., as noted on prior hospitalizations for other conditions) were collected and treated as comorbidities, using an implementation of the Charlson score (23-25). Sex, race/ethnicity, Medicaid receipt, ZIP code median income, and charge and reimbursement data were also developed from the claims. For additional details, with a discussion of limitations, see the online supplement.

\section{Statistical Methods}

We use a variety of approaches to summarize the diverse distribution of outcome variables present in the study: full distribution curves, counts of use, and, for clarity, dichotomization into "no use" versus "any use" $(26,27)$. For additional details on these methods, see the online supplement.

\section{RESULTS}

Our sample consists of 1,108,060 patients newly diagnosed in 1993. The mean age was 79.0 ( \pm 7.1 SD) years; $41.9 \%$ were male; $88.3 \%$ were white; $15.8 \%$ received Medicaid benefits at some point during 1993. Their index diagnoses and other descriptive data are summarized in Table 1 . Of the cohort, $65.1 \%$ died before the end of follow-up; there was no loss to follow-up due to the administrative nature of the records.

\section{Overall Patterns of Use}

Of the cohort, $54.9 \%$ used some critical care from diagnosis until death or the end of follow-up (after at least 4 years). Figure 1A shows the significant variation across diseases in patterns of critical care use during the period of this study. Nearly all acute myocardial infarction patients used at least one critical care hospitalization at some point after their diagnosis. More than half of patients with colon, head and neck, and CNS cancers used critical care services at some point, as did congestive heart failure patients. In every case, at least $30 \%$ experienced some critical care. Therefore, a substantial minority, and in some cases
TABLE 1. COHORT DESCRIPTION*

\begin{tabular}{|c|c|c|}
\hline & Value & Dead $(\%)^{\dagger}$ \\
\hline \multicolumn{3}{|l|}{ Demographics } \\
\hline Age, yr [mean $( \pm S D)]$ & $79.0( \pm 7.1)$ & \\
\hline Male, \% & 41.9 & \\
\hline Medicaid recipients, \% & 15.8 & \\
\hline Income, $\$$ (median of ZIP code) & 30,078 & \\
\hline \multicolumn{3}{|l|}{ Race/ethnicity, \% } \\
\hline White & 88.3 & \\
\hline African American & 7.2 & \\
\hline Asian American & 0.5 & \\
\hline Hispanic & 2.0 & \\
\hline Other race/ethnicity & 1.9 & \\
\hline \multicolumn{3}{|l|}{ Primary diagnosis } \\
\hline \multicolumn{3}{|l|}{ Noncancers, \% } \\
\hline Myocardial infarction & 17.9 & 56.0 \\
\hline Congestive heart failure & 20.8 & 68.4 \\
\hline Hip fracture & 17.4 & 58.2 \\
\hline Stroke & 20.0 & 63.5 \\
\hline \multicolumn{3}{|l|}{ Cancers, \% } \\
\hline CNS & 0.4 & 92.8 \\
\hline Head and neck & 0.8 & 71.6 \\
\hline Liver and biliary tract & 0.7 & 94.0 \\
\hline Colon & 6.6 & 59.8 \\
\hline Leukemia & 1.7 & 78.8 \\
\hline Lung & 6.7 & 90.7 \\
\hline Lymphoma & 2.6 & 78.2 \\
\hline Pancreas & 1.2 & 95.7 \\
\hline Urinary tract & 3.1 & 58.4 \\
\hline
\end{tabular}

${ }^{*} \mathrm{n}=1,108,060$.

${ }^{\dagger}$ By the end of follow-up, after a minimum of 4 years and a maximum of 5 years of surveillance.

a majority, of patients with these common conditions ultimately use critical care services. Similarly, as shown in Figure 1B, significant critical care stays - that is, hospitalizations that included at least 3 days of billed critical care-were not uncommon. More than half of cardiac patients will experience such stays; between one in four and one in five of other patients, including those with hematologic malignancies, will experience such critical care.

As shown in Figure 2, critical care hospitalizations are common during the final 6 months of life among decedents, but a focus on decedents underestimates the true longitudinal incidence by up to half in some diseases. Of cohort members with critical care use, $67.5 \%$ were still alive 6 months after discharge from their first use. What is more, only $31.4 \%(349,443)$ of the cohort's critical care hospitalizations occurred during decedents' final 6 months of life.

Overall in our cohort, $13.6 \%$ of critical care hospitalizations ended in the death of the patient; hospitalizations involving at least 3 days of billed critical care ended in death $13.2 \%$ of the time.

\section{Variation by Age and Other Demographic Variables}

As shown in Table 2, there were significant differences in rates of critical care use. Most strikingly, the odds of using critical care declined markedly with age-patients over age 90 years had less than one-third the odds of using critical care at any point during the study period than did patients aged 68-70 years, even after adjustment for baseline comorbidity. For example, in unadjusted comparisons $47.6 \%$ of lung cancer patients aged $68-70$ years used critical care at some point, whereas only $25.0 \%$ of lung cancer patients aged $86-90$ years and $20.7 \%$ of patients aged 91 years and above did so. (This trend continued for all age groups: $45.1 \%$ of patients $71-75$ years of age; $39.8 \%$ of patients $76-80$ years of age; and $32.1 \%$ of patients $81-85$ years 
A

\begin{tabular}{|c|c|c|}
\hline Acute MI & \begin{tabular}{|l|}
10.5 \\
\end{tabular} & I \\
\hline $\mathrm{CHF}$ & 37.6 & 33.4 \\
\hline CNS Ca & 39.6 & 49.0 \\
\hline Head \& Neck Ca & 44.2 & 36.6 \\
\hline Colon Ca & 47.1 & 36.5 \\
\hline Urinary Tr. Ca & 53.9 & 29.6 \\
\hline Stroke & 54.2 & 29.3 \\
\hline Lung $\mathrm{Ca}$ & 58.7 & 30.6 \\
\hline Lymphoma & 58.9 & 28.3 \\
\hline Leukemia & 60.1 & 27.0 \\
\hline Liver $\mathrm{Ca}$ & 65.3 & 28.1 \\
\hline Hip Fracture & 65.9 & 23.8 \\
\hline Pancreas Ca & 67.9 & 27.5 \\
\hline
\end{tabular}

B

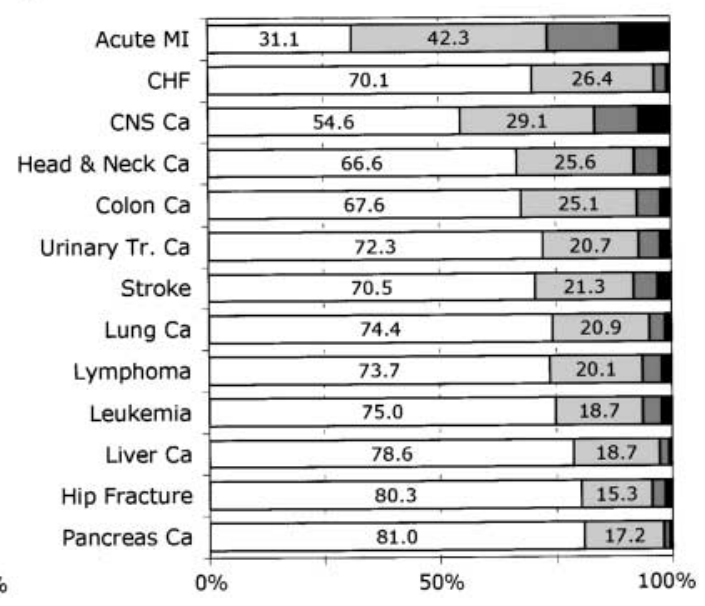

Figure 1. Use of critical care during serious illness ( $\mathrm{n}=$ $1,108,060)$ : percentage of COSI cohort members, by primary diagnosis, who used any critical care services from diagnosis until death or the end of follow-up (maximum of 5 years of follow-up). Cancers of organ systems are denoted by the organ system name (e.g., CNS Ca $=$ cancers of the central nervous system). Number of distinct hospitalizations involving critical care: open bars, zero; light gray bars, one; dark gray bars, two; solid bars, three or more. $\mathrm{Ml}=$ myocardial infarction; $\mathrm{CHF}=$ congestive heart failure. of age.) This pattern persisted in all disease-specific analyses except for colon cancer, where patients 71-90 years of age had $10-30 \%$ greater odds of requiring critical care than did 68to 70-year-olds; this effect occurred only during their initial hospitalization.

African American, Asian American, and white elderly patients appear to use critical care similarly, and less than Hispanic Americans. African Americans were overall more likely to use critical care services (odds ratio, 1.09; 95\% confidence interval, $1.07-1.10 \%$ ) than white individuals in this cohort. A similar absence of substantial difference occurs when comparing Asian Americans with white Americans, albeit with limited sample size for disease-specific analyses. In contrast, Hispanic American elderly were more likely to use critical care services than were white Americans (odds ratio, 1.49; 95\% confidence interval, $1.44-1.53 \%$ ) - statistically significantly so in 9 of 13 diagnoses,

Critical Care Use in Last 6 Months of Life

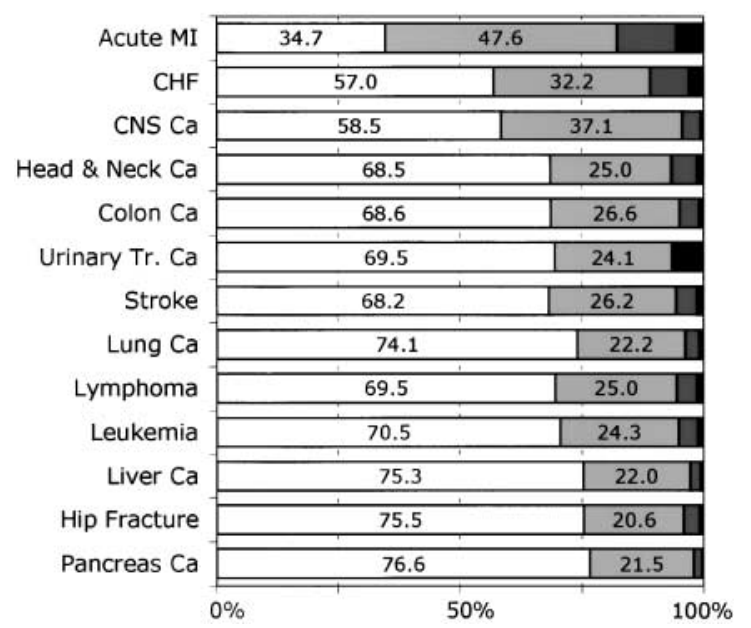

Figure 2. Use of critical care in last 6 months of life by decedents. $\mathrm{n}=$ 721,794 . Percentage of COSI cohort members, by primary diagnosis, who used any critical care services during the last 6 months of their life. COSI cohort members (35\%) who did not die during the study period are excluded. Cancers of organ systems are denoted by the organ system name (e.g., CNS Ca = cancers of the central nervous system). Number of distinct hospitalizations involving critical care: open bars, zero; light gray bars, one; dark gray bars, two; solid bars, three or more. with nonsignificant point estimates in the same direction in the other 4 cases.

Impoverished patients - either those on Medicaid or those who lived in ZIP codes with the lower two quintiles of incomewere less likely to ever use critical care (odds ratio, $0.87 ; 95 \%$ confidence interval, $0.86-0.88 \%$ for Medicaid) after adjustment for covariates. Men were somewhat more likely to use critical care than were women (odds ratio, 1.18; 95\% confidence interval, $1.17-1.19 \%$ ) after adjustment for covariates.

\section{Repeated Users of Critical Care}

A total of 31,348 patients $(2.8 \%$ of the cohort. $5.1 \%$ of all users of critical care) were repeated users of critical care, defined as having five or more distinct hospitalizations in which critical care services were used between diagnosis and death or censoring after no more than 5 years. These repeated users attended a median of two different hospitals for their critical care stays; $34.2 \%$ used one, $24.1 \%$ used three or more. They accounted for

TABLE 2. DEMOGRAPHIC VARIATION IN RATES OF CRITICAL CARE HOSPITALIZATIONS

\begin{tabular}{|c|c|c|c|}
\hline & Odds Ratio & $\begin{array}{c}95 \% \\
\text { Confidence } \\
\text { Interval }\end{array}$ & $\mathrm{p}$ Value \\
\hline \multicolumn{4}{|l|}{ Age, yr } \\
\hline $68-70^{*}$ & 1.00 & & \\
\hline $71-75$ & 0.93 & $0.92-0.95$ & $<0.0001$ \\
\hline $76-80$ & 0.79 & $0.78-0.80$ & $<0.0001$ \\
\hline $81-85$ & 0.63 & $0.63-0.64$ & $<0.0001$ \\
\hline $86-90$ & 0.47 & $0.46-0.48$ & $<0.0001$ \\
\hline$>90$ & 0.31 & $0.31-0.32$ & $<0.0001$ \\
\hline \multicolumn{4}{|l|}{ Race } \\
\hline White* & 1.00 & & \\
\hline African American & 1.09 & $1.07-1.10$ & $<0.0001$ \\
\hline Asian American & 1.06 & $1.00-1.12$ & 0.0573 \\
\hline Hispanic & 1.49 & $1.44-1.53$ & $<0.0001$ \\
\hline Other race & 0.93 & $0.91-0.96$ & $<0.0001$ \\
\hline Medicaid recipient (versus not) & 0.87 & $0.86-0.88$ & $<0.0001$ \\
\hline Men (versus women) & 1.18 & $1.17-1.19$ & $<0.0001$ \\
\hline
\end{tabular}

All variables were run simultaneously in a logistic regression model that also controlled for primary diagnosis, Charlson scores for 3 years before index hospitalization (each year represented by eight dummy variables), and ZIP code median income. All patterns were confirmed in disease-specific regressions as discussed in text.

* Comparison group. 
\$3.66 billion in hospital charges and \$1.45 billion in Medicare reimbursement; these sums were $15 \%$ of all critical care hospitalization charges and reimbursement by the cohort. Furthermore, this minority of users accounted for $23 \%$ of all critical care hospitalizations by cohort members.

As seen in Table 3, in bivariate comparisons relative to other cohort members, repeated users were more likely to be male (46 versus $42 \%$ ), Hispanic (3.6 versus $2.0 \%$ ), younger (75.9 versus 79.1 years), and with higher baseline comorbidity (Charlson score, 0.8 versus 0.5 ) (all $\mathrm{p}<0.001$ ). Cardiac patients were disproportionately represented (75 versus 38\%). Among cancer patients, those suffering from leukemia, lymphoma, colon cancer, and head and neck cancer were most likely to be repeated users. These patterns persisted in multivariate analyses controlling for all measured factors (including Medicaid status and ZIP code median income).

\section{DISCUSSION}

Here, we present the first nationwide longitudinal study of critical care use by seriously ill elderly patients in the United States. There were three key findings in our inception cohort of 1.1 million patients newly diagnosed with common serious illnesses in 1993 and monitored for up to 5 years. First, critical care use is quite common, with half of patients with common cancers or stroke requiring critical care within 5 years of diagnosis. Second, we found that the odds of critical care use declined substantially with increasing age. Third, we found that there exists a meaningful population of repeated users of critical care-those $3 \%$ of patients averaging at least one visit per year for each of 5 years accounted for more than $\$ 3$ billion in hospital charges and accounted for $23 \%$ of all critical care hospitalizations.

These three findings present a useful window through which to view the differences between the longitudinal perspective and other approaches to studying critical care. Episode-focused analyses had indicated that 1 in 10 hospitalizations involved critical care, and noted that this percentage naturally varied as

TABLE 3. CHARACTERISTICS OF REPEATED USERS OF CRITICAL CARE

\begin{tabular}{|c|c|c|c|}
\hline & $\begin{array}{l}\text { Repeat Users } \\
(n=31,348)\end{array}$ & $\begin{array}{c}\text { Others } \\
(n=1,076,712)\end{array}$ & p Value \\
\hline Age, yr & 75.9 & 79.1 & $<0.0001$ \\
\hline Male, \% & 46.4 & 41.7 & $<0.0001$ \\
\hline White, \% & 87.4 & 88.4 & $<0.0001$ \\
\hline African American, \% & 7.4 & 7.2 & 0.0673 \\
\hline Other race, \% & 1.1 & 2.0 & $<0.0001$ \\
\hline Asian American, \% & 0.5 & 0.5 & 0.7143 \\
\hline Hispanic, \% & 3.6 & 2.0 & $<0.0001$ \\
\hline On Medicaid, \% & 15.7 & 15.8 & 0.9284 \\
\hline \multicolumn{4}{|l|}{ Noncancers, \% } \\
\hline AMI & 44.3 & 17.1 & $<0.0001$ \\
\hline $\mathrm{CHF}$ & 31.1 & 20.5 & $<0.0001$ \\
\hline Hip & 4.5 & 17.8 & $<0.0001$ \\
\hline Stroke & 11.9 & 20.3 & $<0.0001$ \\
\hline \multicolumn{4}{|l|}{ Cancers } \\
\hline CNS & 0.1 & 0.5 & $<0.0001$ \\
\hline Head and neck & 0.4 & 0.8 & $<0.0001$ \\
\hline Liver & 0.1 & 0.7 & $<0.0001$ \\
\hline Colon & 2.6 & 6.7 & $<0.0001$ \\
\hline Leukemia & 0.7 & 1.7 & $<0.0001$ \\
\hline Lung & 1.6 & 6.9 & $<0.0001$ \\
\hline Lymphoma & 1.0 & 2.6 & $<0.0001$ \\
\hline Pancreas & 0.1 & 1.3 & $<0.0001$ \\
\hline Urinary tract & 1.6 & 3.2 & $<0.0001$ \\
\hline Mean 1-yr Charlson score & 0.8 & 0.5 & $<0.0001$ \\
\hline Died before end of follow-up, \% & 54.4 & 65.5 & $<0.0001$ \\
\hline
\end{tabular}

a function of the patient's disease burden. It is likewise well known that many serious diseases require multiple hospitalizations over several years of management. However, it has been less appreciated that these facts together imply that the experience of critical care, far from being rare, may well be the modal experience of patients with significant diseases. The diseases represented in COSI include the top three causes of death in the United States (28), and, moreover, are diseases with which millions of Americans struggle for years. Thus, although few Americans may use critical care in any given year, these data make plausible the contention that a majority of Americans likely will use critical care over the course of a life.

The relatively common use of critical care highlights differences from the perspective provided by SUPPORT. The focus of SUPPORT on end-of-life care - with nine enrolling diagnoses at five tertiary care centers carefully selected to yield an intended $50 \%$ 6-month mortality-meant that critical care would be viewed as part of the dying process, a preterminal event. Our data clearly show that critical care use, although certainly indicative of serious illness, can also occur earlier in the course of disease; more than two-thirds of patients will survive their critical care hospitalization by more than 6 months. Critical care hospitalizations during the last 6 months of life are not "typical" critical care visits, and, as such, care should be taken in generalizing from the SUPPORT experiences of the gravely ill at five academic medical centers to all critical care services nationwide.

The generalizability of SUPPORT is of particular importance as there were several troubling issues raised by SUPPORT, including the quality of patient-physician communication about preferences for aggressiveness of care (29) and the quality of pain control at the end of life (3). SUPPORT also raised profound concerns about differential treatment of the elderly. Several studies have noted marked differences in rates of Do Not Resuscitate orders as a function of age (30). Although some of these differences appear to be a function of true differences in patient preferences (30), there is also evidence that physicians tend to underestimate the desire of the elderly for aggressive care (31). These physician-patient disconnects may have measurable adverse mortality impacts (32). More generally, there is evidence that the elderly are treated less aggressively (33), despite the significant evidence that age, per se, has a relatively minor impact on the efficacy of critical care interventions (34-36). These past studies have been limited to modest samples, typically in a few institutions $(33,37,38)$. Our data, although lacking detailed preference information provided by SUPPORT, do strongly sustain the concerns raised by SUPPORT and others about the differential access of the elderly to potentially life-saving critical care on a nationwide basis. These data reinforce the fact that the failure of the SUPPORT intervention (3) only makes innovative research on this issue all the more urgently needed.

In contrast to these marked age gradients, other demographic factors were of modest importance. Race and ethnicity gradients were clearly present, and ought be examined critically in light of their pernicious pervasiveness in medicine (39). Nonetheless, in magnitude they accord with certain other modest findings (40). Similarly, potentially concerning lower levels of utilization were found among the impoverished, which warrants further examination; socioeconomic gradients have been found among Do Not Resuscitate orders in other study populations (41).

More generally, the longitudinal perspective on critical care research naturally draws attention to the possibility that there would exist a subset of patients who disproportionately utilize critical care resources. Episode-focused analyses have emphasized that a minority of long-stay users account for perhaps one-quarter or more of bed days in surgical ICUs (42). As others have emphasized, this is not only extremely expensive, but it also limits the 
access of other patients to potentially life-saving critical care nursing and beds (42). These long stays have also been identified as "potentially ineffective care," and have been the target of numerous studies $(9,43,44)$. Significant effort has been devoted to finding lower intensity ways - such as intermediate care units or long-term ventilatory facilities - to care for such patients without compromising their health. The longitudinal focus identifies a distinct but parallel subset of patients who use disproportionate fractions of critical care resources, but divide them into many stays, sometimes in multiple institutions. Although our data do not allow us to reliably quantify the fraction of critical care days for which they account, this small minority of patients accounted for more than $20 \%$ of all critical care hospitalizations in the cohort. What is more, they accounted for more than $\$ 3$ billion in hospital charges. Given, as well, the iatrogenic and nosocomial risks of critical care $(1,45,46)$, it raises the question of whether these patients could be safely managed in lower acuity settings, as has been done with guidelines stemming from individual episodes of care (47-50). As cost control measures begin to be applied to critical care services (51), the present data suggest that efforts to better manage the longitudinal course of care of repeated users could offer significant benefits. More finely grained longitudinal patient data are necessary to identify repeated users so that prevention of the need for critical care can be integrated into outpatient multidisciplinary chronic disease management (52).

\section{Limitations and Directions for Future Research}

This work is subject to several limitations. First, we examined longitudinal use of critical care pertaining only to 13 conditions among the elderly. Although those conditions represent the most common causes of death in the United States, they are not allinclusive of patients at risk for critical care use. In particular, we have chosen a group of diseases that allow clear definition of onset of disease within the measurement limitations of Medicare claims; future work should relax this restriction to include other important causes of ICU admission (and repeated admissions) such as chronic obstructive pulmonary disease, liver disease, and renal disease. Likewise, we studied only the elderly-clearly, significant amounts of critical care may be used by those under the age of 68 years. Regrettably, data to study national patterns of health care utilization by young and middle-aged patients are more scarce.

Second, by using Medicare claims we gain the benefits of national enumerations and high data quality. However, we suffer from disadvantages that require future work, including limited clinical and social detail, and we have no separate information about patient's wishes (18). We cannot decompose "critical care hospitalization" more finely, looking at precise indications (53) or utilization of procedures (54).

Third, we have studied critical care hospitalizations, rather than individual days spent in a given unit. Although this offers us independence from known hospital-to-hospital variation in ICU discharge patterns and variation resulting from high ICU bed occupancy or limited availability in a given hospital, such detailed local studies would clearly be of complementary value, particularly in deriving implications for the practice of individual physicians with particular patients. Similarly, as our focus in this article is on longitudinal course, we have focused on whether patients ever use critical care, and the number of times. Complementary studies on rates of critical care use per unit time or per hospitalization would be of value.

Finally, ours is an observational and descriptive study; as such, we cannot say whether, in any substantial sense, the patterns we observe are normatively the "right" ones. We have not addressed outcomes of critical care, as others have done in more focused studies $(36,55)$; the current study has not estimated the impact of current patterns of critical care use on mortality or morbidity of patients.

Despite its limitations, the longitudinal perspective offers a complementary view to the study of critical care, and a framework within which to integrate more focused studies. Others have argued forcefully that critical care services need to be linked to long-term outcomes, understanding diverse possibilities and perspectives (56-58). The present work seeks to extend that insight, to embed the common experience of critical care use not only as the beginning of a process, but within the overriding disease trajectory of seriously ill patients.

Conflict of Interest Statement: T.J.I. does not have a financial relationship with a commercial entity that has an interest in the subject of this manuscript.

Acknowledgment: The author thanks Laurie Meneades for expert computing assistance. Helpful criticism was received from Drs. Nicholas Christakis, Virginia Chang, Peter Ehrenkranz, and Giora Netzer.

\section{References}

1. Berenson RA. Intensive care units (ICUs): clinical outcomes, costs, and decisionmaking. Health Technology Case Study 28. Washington DC: Congressional Office of Technology Assessment; 1984.

2. Jacobs P, Noseworthy TW. National estimates of intensive care utilization and costs: Canada and the United States. Crit Care Med 1990;18:12821286.

3. SUPPORT Principal Investigators. A controlled trial to improve care for seriously ill hospitalized patients. JAMA 1995;274:1591-1598.

4. Levy MF, Greene L, Ramsay MAE, Jennings LW, Ramsay KJ, Meng J, Tillmann Hein HA, Goldstein RM, Husberg BS, Gonwa TA, et al. Readmission to the intensive care unit after liver transplantation. Crit Care Med 2001;29:18-24.

5. Rosenberg AL, Hofer TP, Hawyard RA, Strachan C, Watts CM. Who bounces back? Physiologic and other predictors of intensive care unit readmission. Crit Care Med 2001;29:511-518.

6. Rosenberg AL, Watts C. Patients readmitted to ICUs: a systematic review of risk factors and outcomes. Chest 2000;18:492-502.

7. Cooper GS, Sirio CA, Rotondi AJ, Shepardson LB, Rosenthal GE. Are readmissions to the intensive care unit a useful measure of hospital performance? Med Care 1999;37:399-408

8. Chen L, Martin C, Keenan S, Sibbald W. Patients readmitted to the intensive care unit during the same hospitalization: clinical features and outcomes. Crit Care Med 1998;26:1834-1841.

9. Arabi Y, Venkatesh S, Haddad S, al Shimemeri A, al Malik SO. A prospective study of prolonger stay in the intensive care unit: predictors and impact on resource utilization. Int J Qual Health Care 2002;14:403410.

10. Rapoport J, Teres D, Barnett R, Jacobs P, Shustack A, Lemeshow S, Norris C, Hamilton S. A comparison of intensive care unit utilization in Alberta and western Massachusetts. Crit Care Med 1995;23:1336-1346.

11. Iwashyna TJ. Older patients are much less likely to use critical care: nationwide longitudinal cohort data [abstract]. Am J Respir Crit Care Med 2004;169(Suppl):A52.

12. Hatten J. Medicare's common denominator: the covered population. Health Care Financ Rev 1980; Fall:53-64.

13. Christakis NA, Iwashyna TJ, Zhang JX. Care after the Onset of Serious Illness (COSI): A novel claims-based data set exploiting substantial cross-set linkages to study end-of-life care. J Palliat Med 2002;5:515530.

14. McBean AM, Babish JD, Warren JL. Determination of lung cancer incidence in the elderly using Medicare claims data. Am J Epidemiol 1993;137:226-234.

15. McBean AM, Warren JL, Babish JD. Measuring the incidence of cancer in elderly Americans using Medicare claims data. Cancer 1994;73: 2417-2425

16. Benesch C, Witter DM Jr, Wilder AL, Duncan PW, Samsa GP, Matchar DB. Inaccuracy of the International Classification of Disease (ICD-9$\mathrm{CM}$ ) in identifying the diagnosis of ischemic cerebrovascular disease. Neurology 1997;49:660-664.

17. Krumholz HM, Radford MJ, Wang Y, Chen J, Heiat A, Marciniak TA. National use and effectiveness of the beta-blockers for treatment of elderly patients after acute myocardial infarction. JAMA 1998;280: 623-629.

18. Lauderdale DS, Furner SE, Miles TP, Golderberg J. Epidemiologic uses of Medicare data. Epidemiol Rev 1993;15:319-327. 
19. Committee on Manpower for Pulmonary and Critical Care Societies (COMPACCS). Future needs in pulmonary and critical care medicine. Cambridge, MA: Abt Associates; 1998.

20. Angus DC, Linde-Zwirble WT, Sirio CA, Rotondi AJ, Chelluri L, Newbold RCI, Lave JR, Pinsky MR. The effect of managed care on ICU length of stay: implications for Medicare. JAMA 1996;276:1075-1082.

21. Code of Federal Regulations. 42 CFR ${ }^{\S} 413.53(d)$ : Criteria for identifying intensive care type units. Washington DC: Government Printing Office; 2002. Available at: http://www.access.gpo.gov/nara/cfr/waisidx_02/ 42cfr413_02.html (accessed August 2004).

22. Detsky AS, Stricker SC, Mulley AG, Thibault GE. Prognosis, survival, and the expenditure of hospital resources for patients in an intensivecare unit. N Engl J Med 1981;305:667-672.

23. Charlson ME, Pompei P, Ales KL, MacKenzie CR. A new method of classifying prognostic comorbidity in longitudinal studies: development and validation. J Chronic Dis 1987;40:373-383.

24. Deyo RA, Cherkin DC, Ciol MA. Adapting a clinical comorbidity index for use with ICD-9-CM administrative databases. J Clin Epidemiol 1992;45:613-619.

25. Zhang JX, Iwashyna TJ, Christakis NA. The impact of alternative lookback periods and sources of information on Charlson comorbidity adjustment in Medicare claims. Med Care 1999;37:1128-1139.

26. Agresti A. Categorical data analysis. New York: Wiley-Interscience; 1990

27. Allison PD. Logistic regression using the SAS system: theory and applications. Cary, NC: SAS Institute; 1999.

28. Hoyert DL, Arias E, Smith BL, Murphy SL, Kochanek KD. Deaths: final data for 1999. Natl Vital Stat Rep 2001;49:1-113.

29. Covinsky KE, Fuller JD, Yaffer K, Johnston CB, Hamel MB, Lynn J, Teno JM, Phillips RS. Communication and decision-making in seriously ill patients: findings of the SUPPORT project. The Study to Understand Prognoses and Preferences for Outcomes and Risks of Treatments. J Am Geriatr Soc 2000;48:S187-S193.

30. Phillips RS, Wenger NS, Teno JM, Oye RK, Younger S, Califf R, Layde $\mathrm{P}$, Connors AFJ, Lynn J, for SUPPORT (Study to Understand Prognoses and Preferences for Outcomes and Risks of Treatments) Investigators. Choices of seriously ill patients about cardiopulmonary resuscitation: correlates and outcomes. Am J Med 1996;100:128-137.

31. Hamel MB, Teno JM, Goldman L, Lynn J, Davis RB, Galanos AN, Desbeins N, Connors AFJ, Wenger N, Phillips RS, for SUPPORT Investigators. Patient age and decisions to withhold life-sustaining treatments from seriously ill, hospitalized adults. Ann Intern Med 1999; 130:116-125.

32. Hamel MB, Davis RB, Teno JM, Knaus WA, Lynn J, Harrell FJ, Galanos AN, Wu AW, Phillips RS, for SUPPORT Investigators. Older age, aggressiveness of care, and survival for seriously ill, hospitalized adults. Ann Intern Med 1999;131:721-728.

33. Ozua EI, Chelluri L. Age bias in the limitation of life support: a systematic review of the literature. Chest 2000;118:126S.

34. Chelluri L, Mendelsohn AB, Belle SH, Rotondi AJ, Angus DC, Donahoe MP, Sirio CA, Schulz R, Pinsky MR. Hospital costs in patients receiving prolonged mechanical ventilation: does age have an impact? Crit Care Med 2003;31:1746-1751.

35. Chelluri L, Grevnik A, Silverman M. Intensive care for critically ill elderly: mortality, costs, and quality of life [review of the literature]. Arch Intern Med 1995;155:1013-1022.

36. Chelluri L, Pinsky M, Donahoe M, Grenvik A. Long-term outcome of critically ill elderly patients requiring intensive care. JAMA 1993;269: 3119-3123.

37. Castillo-Lorente E, Rivera-Fernandez R, Vazquez-Mata G. Limitation of therapeutic activity in elderly critically ill patients. Crit Care Med 1997;25:1643-1648.

38. Hanson LC, Danis M. Use of life-sustaining care for the elderly. J Am Geriatr Soc 1991;39:772-777.

39. Smedley BD, Stith AY, Nelson AR, editors. Unequal treatment: confronting racial and ethnic disparities in health care. Washington DC: National Academy Press; 2003.

40. Rathore SS, Foody JM, Wang Y, Smith GL, Herrin J, Masoudi FA,
Wolfe P, Havranek EP, Ordin DL, Krumholz HM. Race, quality of care, and outcomes of elderly patients hospitalized with heart failure. JAMA 2003;289:2517-2524.

41. Mark DH, Bahr J, Duthie EH, Tresch DD. Characteristics of residents with do-not-resuscitate orders in nursing homes. Arch Fam Med 1995; 4:463-467.

42. Weissman C. Analyzing the impact of long-term patients on ICU bed utilization. Intensive Care Med 2000;26:1319-1325.

43. Cher DJ, Lenert LA. Method of Medicare reimbursement and the rate of potentially ineffective care of critically ill patients. JAMA 1997;278: 1001-1007.

44. Teno JM, Fischer E, Hamel MB, Wu AW, Murphy DJ, Wenger NS, Lynn J, Harrell FEJ. Decision-making and outcomes of prolonged ICU stays in seriously ill patients. J Am Geriatr Soc 2000;48:S70-S74.

45. Kapadia F, Bajan K, Raje KV. Airway accidents in intubated intensive care unit patients: an epidemiological study. Crit Care Med 2000;28: 659-664.

46. Cullen DJ, Sweitzer BJ, Bates DW, Burdick E, Edmondson A, Leape LL. Preventable adverse drug events in hospitalized patients: a comparative study of intensive care and general care units. Crit Care Med 1997;25:1289-1297.

47. Inayet N, Amoateng-Adjepong Y, Upadya A, Manthous CA. Risk for developing critical illness with GI hemorrhage. JAMA 2000;118:473478.

48. Rosenthal GE, Sirio CA, Shepardson L, Harper DL, Rotondi AJ, Cooper GS. Use of intensive care units for patients with low severity of illness. Arch Intern Med 1998;158:1144-1151.

49. Braunwald E, Antman EM, Beasley JW, Califf RM, Cheitlin MD, Hochman JS, Jones RH, Kereiakes D, Kupersmith J, Levin TN, et al. ACC/AHA 2002 guideline update for the management of patients with unstable angina and non-ST-segment elevation myocardial infarction: a report of the American College of Cardiology/American Heart Association Task Force on Practice Guidelines (Committee on the Management of Patients with Unstable Angina). Available at: http://www.acc.org/clinical/guide lines/unstable/unstable.pdf (accessed August 2004).

50. Ryan TJ, Antman EM, Brooks NH, Califf RM, Hillis LD, Hiratzka LF, Rapaport E, Riegel B, Russell RO, Smith EEI, et al. Committee on Management of Acute Myocardial Infarction, American College of Cardiology. ACC/AHA guidelines for the management of patients with acute myocardial infarction: 1999 update - a report of the American College of Cardiology/American Heart Association Task Force on Practice Guidelines.

51. Rosenberg A, Zimmerman J, Alzola C, Draper E, Knaus W. Intensive care unit length of stay: recent changes and future challenges. Crit Care Med 2000;28:3465-3473.

52. Bodenheimer T, Wagner EH, Grumbach K. Improving primary care for patients with chronic illness. JAMA 2002;288:1775-1779.

53. Weissman C. Can hospital discharge diagnoses be used for intensive care unit administrative and quality management functions? Crit Care Med 1997;25:1320-1323.

54. Cullen DJ, Civetta JM, Briggs BA, Ferrara LC. Therapeutic intervention scoring system: a method for quantitative comparison of patient care. Crit Care Med 1974;2:57-60.

55. Herridge MS, Cheung AM, Tansey CM, Matte-Martyn A, Diaz-Granados N, Al-Saidi F, Cooper AB, Guest CB, Mazer CD, Mehta S, et al., for Canadian Critical Care Trials Group. One-year outcomes in survivors of the acute respiratory distress syndrome. N Engl J Med 2003;348:683693.

56. Angus DC, Carlet J, for 2002 Brussels Roundtable Participants. Surviving intensive care: a report from the 2002 Brussels Roundtable. Intensive Care Med 2003;29:368-377.

57. Angus DC, Carlet J, Schroder JC, editors. Surviving intensive care: update in intensive care and emergency medicine. New York: SpringerVerlag; 2002.

58. Cook DJ. Transdisciplinary research to understand the role of bias and heuristics. In: Curtis JR, Rubenfeld GD, editors. Managing death in the ICU: the transition from cure to comfort. Oxford: Oxford University Press; 2001. p. 59-68. 